be returned to the author WITHOUT EXCEPTION".

I have looked at the two sets of guidelines and obviously there is some overlap but I am left with the feeling that the left hand does not know what the right hand is doing!

KErTH J. B. RIX, Consultant Psychiatrist, Leeds Community \& Mental Health Services, Ilkley. West Yorkshire LS29 6AQ

\section{Driving and dementia: DVLA guidelines?}

Sir: Paul Thompson and Deborah Nelson (Psychiatric Bulletin, June 1996, 20, 323-325) report their questionnaire survey of psychiatrists' knowledge of DVLA regulations. They state that in early dementia "driving is permitted if no significant disorientation and insight and judgment are retained". This is a quotation from the literature, forming part of a discussion in Medical Aspects of Fitness to Drive (Taylor, 1995), but is by no means a clear guideline. There is no clear relationship between the degree of dementia and driving ability, nor is psychometric testing particularly helpful (Friedland, 1988).

It seems at the moment that the best ways of assessing fitness to drive in dementia are a combination of history of driving ability from the patient and caregiver, and in uncertain cases onroad or off-road driving tests (Odenheimer, 1993). There is also the possibility of a driving simulator test, although this is not routinely used in this country.

Friedland, R. P. (1988) Motor Vehicle Crashes in Dementia of the Alzheimer Type. Annals of Neurology. 24. 782-786.

ODEnHEIMER, G. L. (1993) Dementla and the older driver. Clinics in Geriatric Medicine, 9(2), 349-364.

TAYLOR. J. F. (ed.) (1995) Medical Aspects of Fitness to Drive. London: The Medical Commission on Accident Prevention.

WALTER BOUMAN and HAZEL JOHNSON. Department of Health Care of the Elderly. Queen's Medical Centre, Nottingham NG7 2UH

\section{Care Programme Approach (CPA) in the community}

Sir: We were interested to read the correspondence from Mark Evans and his colleagues on the CPA (Psychiatric Bulletin. July 1996, 20. 444-445). We have recently conducted a survey of members of staff about their opinions on the benefits and problems associated with CPA implementation. Our survey indicated that many staff were experiencing severe logistical difficulties with the Care Programme Approach. Ninety- three per cent of the sample ( $n=45)$ agreed that administrative tasks, such as arranging and attending meetings and completing documentation, were putting extra demands on their time, to the degree that it decreased their contact with patients. The reason for this appeared to be the policy of assessing and recording the needs of every patient within a large Trust, currently having over 9000 contacts each year. It seemed to us that attention was being paid to the bureaucratic external manifestations of the CPA for all patients, to the detriment of improving service provision for those in most need.

The demands made on professionals by CPA administrative tasks are impractical. For example, discussion of CPA generated matters added 110 minutes to a multidisciplinary meeting involving 14 professionals, some of whom had cancelled ward rounds and home visits to be there. Thus, in one day 25.7 hours of time had been effectively lost to patient care.

In our view, given the limited resources and manpower available, care programming must be effectively targeted at the most vulnerable patients. The ideal of always tailoring care to the needs of every individual patient, while laudable, may not always be realistically achieved.

Claire EAston and FEMI OYEBODE, South Birmingham Mental Health NHS Trust, Research and Development Unit, Edgbaston B15 2QZ

\section{Supervision registers}

Sir: I read with interest Mr Vaughan's survey of the application of the supervision register in four Regional Health Authorities (Psychiatric Bulletin. March 1996, 20, 143-145). I have also addressed the question of how the Health Service Guidelines concerning supervision registers have been implemented by auditing the register of one Trust. This revealed similar findings to Vaughan's study - a register "absorbed organisationally but less accepted professionally".

The Trust in which I conducted the audit serves a catchment area of 100000 people. There are three consultant psychiatrists. The supervision register was implemented in accordance with the Health Service Guidelines on 1 October 1994. In May 1995, 12 patients were registered - one 54year-old woman and 11 men, six of whom were in their forties. Six of the patients had a diagnosis of schizophrenia, two had a diagnosis of affective disorder and two had a diagnosis of alcohol abuse or dependency. Seven had been detained under the Mental Health Act 1983 at the time of inclusion on the register. For each patient the reason for inclusion on the register was clearly documented - significant risk of suicide, serious harm to others and/or risk of serious self-neglect. 
The register included details of the patient's Care Programme together with the name, address and telephone number of the consultant, keyworker and general practitioner. A system of six monthly consultant reviews was up and running.

Turning to the professional acceptance of this impressively organised register, neither I nor any of my four colleagues then on the duty-doctor rota knew the whereabouts of the register until after the audit; it was a red A4 ring-bound flle, labelled "Supervision Register" and stored on a shelf in the secretarial office above the wards and out-patient rooms.

I agree with Mr Vaughan's conclusion that more energy needs to be expended into education about the purpose and use of the supervision register-not only for other services, as he suggests, but also for those of us providing the psychiatric care.

ROGER DENNY, Registrar, Fromeside Clinic, Blackberry Hill, Stapleton, Bristol BS16 1ED

\section{Changing medical students' attitudes to learning disability}

Sir: We were pleased to see the paper by Hall \& Hollins (Psychiatric Bulletin. July 1996, 20. 429-430) on the impact of the Strathcona Theatre workshops on medical students' attitudes to learning disability. Having received the idea from Professor Hollins, our experience from using the company in undergraduate medical teaching over the last 9 years, is also positive and we endorse the authors' findings. Successive firms of students have found the workshops interesting, well organised and very useful.

Furthermore in our programme, two people with mild learning disabilities spend a morning with small groups of students taking them to a day centre, a respite care and a local in-patient assessment facility. We believe that these occasions provide a positive image of people with learning disability and a further opportunity for the latter to be in control.

Current changes in the medical curriculum pose threats as well as opportunities for teaching about learning disabilities. It is essential that such positive encounters remain part of the core teaching and more in-depth experiences are made available as special modules. Teaching on the long-term consequences of chronic disability and the medical role in this could be done through short-term contacts, i.e. five or six visits to a disabled person in a family or in residential care properly supervised over a year.

As the face of practice in the psychiatry of learning disability alters, it is of great importance that teaching addresses and facllitates the inclusion of learning disability in a modern medical curriculum.

JaCK PIACHAUd, St Charles Hospital, Exmoor Street, London W10 6DZ, and ANGELA HASSIOTIS, Eric Short House, Harrow Hospital, Roxeth Hill, Harrow HA2 OSX

\section{Missing 19}

Sir: I read with interest, Dr West's correspondence on the subject of missing IQ (Psychiatric Bulletin, June 1996, 20, 370-371). The IQ went missing as the psychologists became more clinical'. Furthermore, he lost his identity as terms such as 'borderline', 'low-normal' and 'subnormal' etc. came into being without clear meaning. Although the Code of Practice (Department of Health and Welsh Office, 1990) recommended that "No patient should be classified under the Act as mentally impaired or severely mentally impaired in the absence of formal psychological assessment", still many patients are so diagnosed with IQ missing. Should psychiatrists depend upon fellow psychologists to search for the IQ?

As a psychiatrist in Learning Disabilities, I always keep track of his whereabouts through my own efforts. With a little practice, he is so easy to find.

Department of Hentth and Weish OfFice (1990) Code of Practice. Mental Health Act 1983. London: HMSO.

ANIL KUMAR, Calderstones NHS Trust, Whalley, Clitheroe BB7 9PE 